\title{
Quadruple sectoranopia and sectorial optic atrophy: a syndrome of the distal anterior choroidal artery
}

\author{
L . FRISÉN \\ From the Department of Ophthalmology, University of Göteborg, Sweden
}

SUMMARY Loss of upper and lower homonymous sectors in the visual field, and wasting of corresponding sectors in the retinal nerve fibre layer, followed ligation of the distal part of the anterior choroidal artery in a patient with a meningioma of the velum interpositum. Clinical and radiological evidence indicated that the visual pathway was damaged within that part of the lateral geniculate body that is served by the anterior choroidal artery.

A syndrome of sectorial optic atrophy and homonymous, horizontal sectoranopia has recently been described in this journal, and attributed to infarction of the territory of the lateral choroidal artery in the dorsal lateral geniculate nucleus (LGN) (Frisén et al., 1978). Ischaemia within that part of the LGN that is served by the anterior choroidal artery should give the opposite picture: loss of upper and lower homonymous sectors in the visual field with corresponding sectorial optic atrophy. Such a case has not been described previously but the following observations indicate that the prediction is correct.

\section{Case report}

A 31 year old engineer awoke one morning in 1972 with headache and a sensation of clumsiness in his left hand. He had previously been in excellent health. Examination by a neurologist a few weeks later disclosed a minimal left hemiparesis, impaired stereognosis on the left, and a left homonymous hemianopia. Bilateral papilloedema of moderate degree was also noted. A radioisotope study showed early uptake of considerable magnitude in the deep parietal area on the right. Right carotid angiography demonstrated a $15 \mathrm{~mm}$ displacement to the left of the midline vessels, and upward shift of middle cerebral artery branches. The cause of these changes was a wellvascularised lesion in the right ventricular trigone. The lesion was fed primarily from small, tortuous

Address for reprint requests: Dr L. Frisén, Ögonkliniken, Sahlgrenska sjukhuset, S-413 45 Göteborg, Sweden.

Accepted 25 January 1979 vessels coming from the distal anterior choroidal artery, which was strikingly dilated (Fig. 1A). Other portions of the tumour were fed from small tortuous vessels coming from the carotid syphon and branches of the middle cerebral artery. There was neither arteriovenous shunting nor fillingo from external carotid artery branches. The findings were considered compatible with an intraventricular meningioma.

A preoperative neuro-ophthalmological examination showed a complete left homonymous hemianopia. Optokinetic stimulation gave a less vigorous response when the drum was rotated towards the right. Both optic nerve heads were swollen, protruding about three dioptres. The cup of the optic disc was nearly obliterated, but only short vascular segments were obscured by overlying oedema. There was a moderate degree of hyperaemia, a few yellow spots, and a few thin splinter haemorrhages at the disc borders. No other abnormalities were seen.

Neurosurgical exploration was made through a $30 \mathrm{~mm}$ diameter circular incision through the upper posterior part of the temporal lobe. An intraventricular meningioma with a diameter of about $50 \mathrm{~mm}$ was encountered about $10 \mathrm{~mm}$ from the cortical surface. The tumour was very vascular and much bleeding occurred during the successive reduction of its size. After partial piecemeal removal, its vascular attachment could be visualised and ligated: it was seen to include the distal part of the anterior choroidal artery. The remainder of the tumour could then be lifted out. The tumour was partly intraventricular, adherent to the choroid plexus just anterior to the lateral geniculate body, but also partly embedded in the bottom 

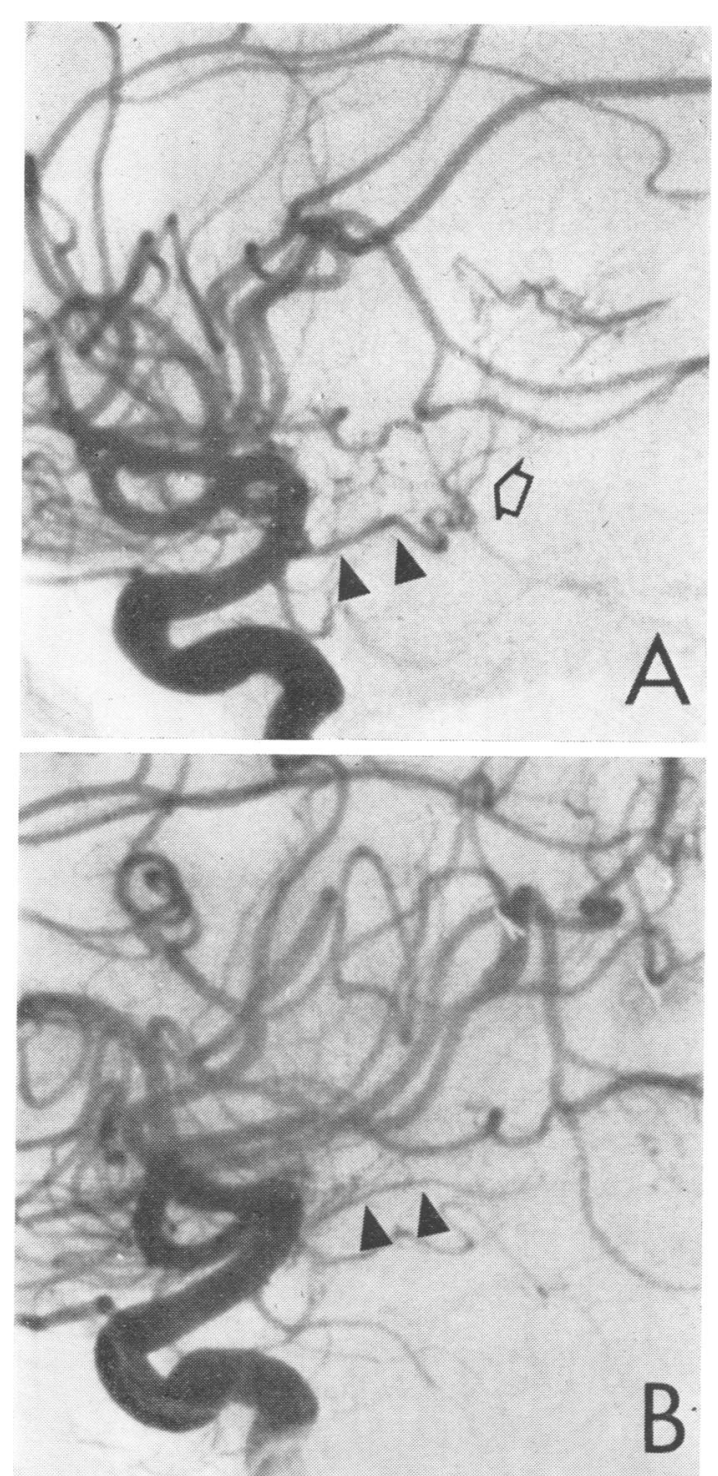

Fig. 1 Right internal carotid angiograms in lateral projection. A: preoperative dilatation and tortuosity of anterior choroidal artery (arrowheads). Distal branches (open arrow) feed an intraventricular tumour. B: postoperatively, the stem of the anterior choroidal artery has a normal appearance, but there is no filling of distal branches.

of the ventricle. It was judged to be a typical meningioma of the velum interpositum, in the terminology of Cushing and Eisenhardt (1938). Microscopic examination showed an atypical haemangiopericytoma.
The patient made an uneventful recovery. Four months after operation the papilloedema had disappeared. The left homonymous hemianopia was partly restituted, with the emergence of homonymous, horizontal strips with abruptly sloping borders. This left the patient with blind sectors in the upper and lower parts of the left hemifields, a deficit that can be designated quadruple sectoranopia (Fig. 2).

There was no change during the following years, but in 1978 the patient noticed a swelling in the region of the flap. Computed tomography showed a highly vascular tumour in the corresponding area, together with a clinically unsuspected recurrence of about $30 \mathrm{~mm}$ diameter at the site of the original tumour. Angiograms showed nonfilling of the distal anterior choroidal artery on the right (Fig. 1B), with a normal appearance of the lateral choroidal artery. The intraventricular recurrence was now fed primarily from tortuous branches from the lateral choroidal artery, together with branches coming directly from the posterior cerebral artery.

The preoperative neuro-ophthalmological examination disclosed no change in the visual field defect. Partial loss of the peripapillary retinal nerve fibre layer was observed and photographed (Fig. 3). The areas of atrophy correspond to the distribution of the visual field defects. The optic discs were neither pale, nor swollen. No other abnormality was found.

After neurosurgical removal of the recurrent tumours, the patient made an excellent recovery. There was no change in his neuro-ophthalmological status after surgery.

\section{Discussion}

The complete left homonymous hemianopia which was present before operation could be attributed to conduction failure. The role of ischaemia in conduction failure has recently been emphasised (Frisén et al., 1976; Roski et al., 1978). The exposed position in the tumour bed of vessels feeding the optic tract, the LGN, and the proximal optic radiation is relevant in this regard (Zeal and Rhoton, 1978).

Recovery of the hemianopia after operation was incomplete. This might have been the result of optic atrophy associated with papilloedema, damage to the optic radiation associated with the surgical approach, or partial infarction of the LGN associated with the ligation of the distal anterior choroidal artery.

It is unlikely that raised intracranial pressure was responsible because of the short history, the absence of early retinal nerve fibre atrophy, and 


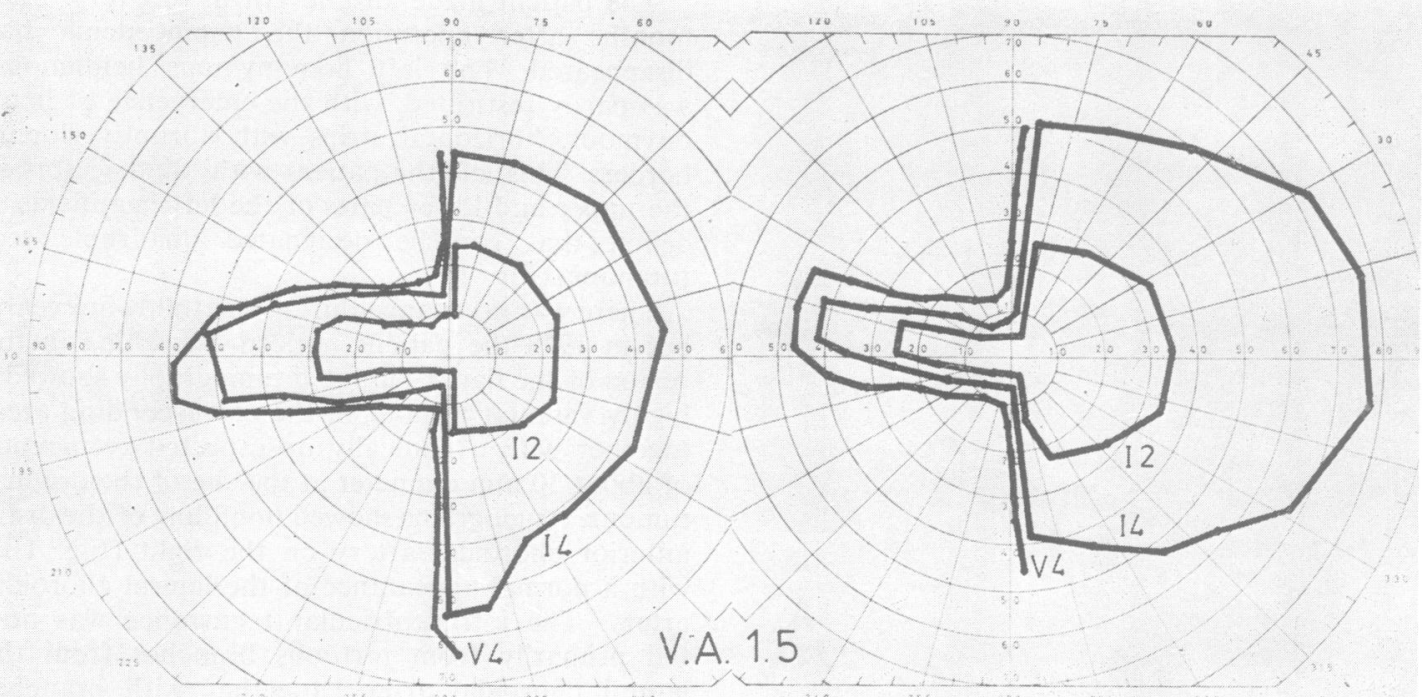

Fig. 2 Quadruple sectoranopia. Test targets given in Haag-Streit designation.
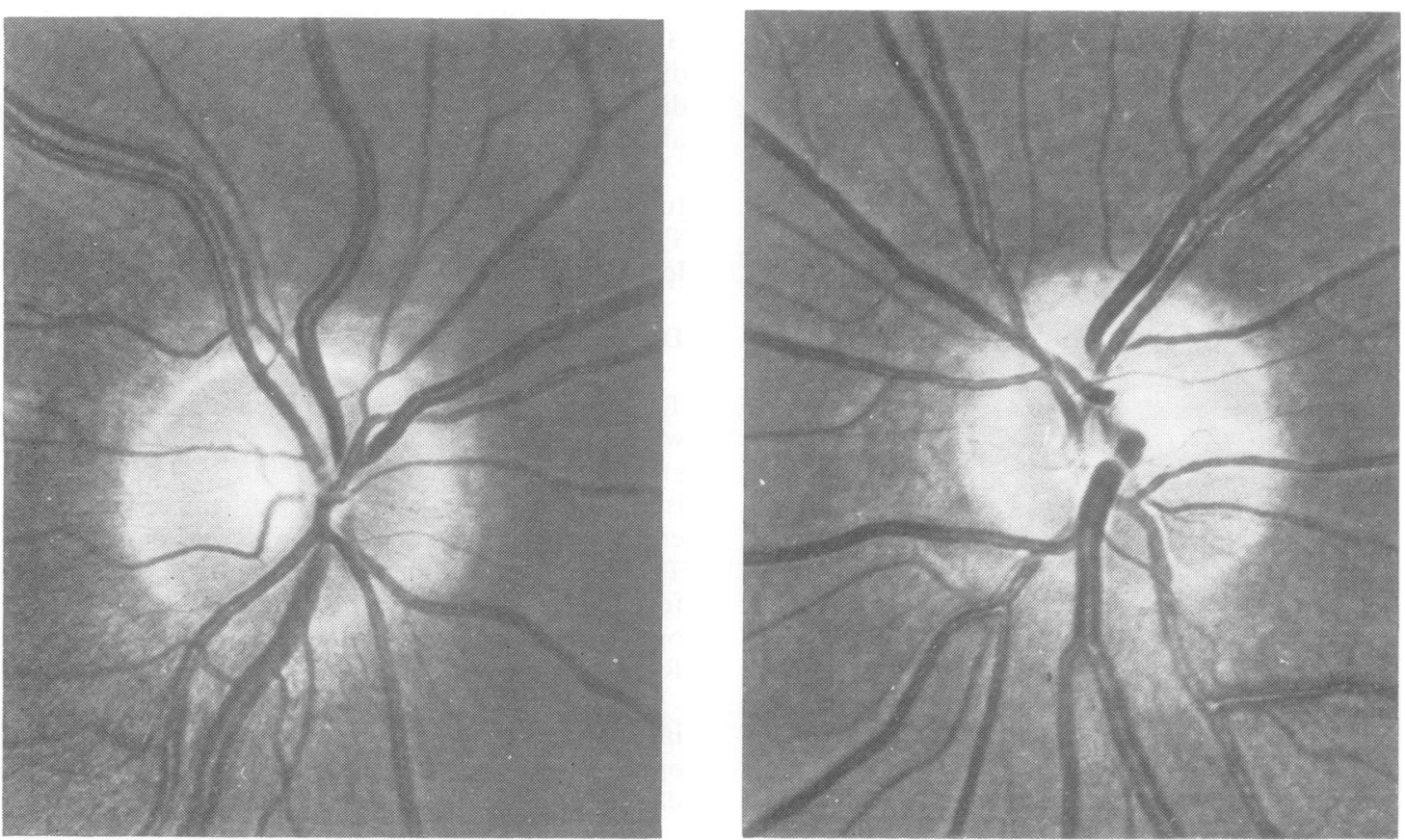

Fig. 3 Fundus photographs $(\times 20)$ showing severe atrophy of retinal nerve fibre bundles in broad sectors above the optic discs, and partial atrophy below. The wasted areas appear to have a more temporal distribution in the right eye (left picture), the eye with the nasal visual field defect. Loss of nerve fibre bundles is evidenced by lack of fine, grey lines radiating from the optic disc, with consequent exposure of small retinal vessels. 
the congruence of the visual field defects. Chronic papilloedema may cause visual field defects (Traquair, 1949; Bynke, 1966), as may any associated retinochoroidal folds (Frisén and Holm, 1977), but neither of these abnormalities was present.

Visual field defects caused by temporal lobe incisions usually have the appearance of homonymous, upper sectorial defects with sloping lower borders (Falconer and Wilson, 1958; Van Buren and Baldwin, 1958). Knowledge of the anatomy of the visual pathway is not sufficiently detailed in the region incised in the present case to allow confident prediction of the type of visual field defect to be expected but homonymous hemianopias are not uncommon (Löfgren, personal communication). In the present case, it is possible that the herniation of the lateral ventricle below the falx may have moved the optic radiation out of the incised area. In any event, a lesion of the optic radiation would not be compatible with the development of retinal nerve fibre atrophy: in adults, atrophy is associated solely with anterior visual pathway lesions (Hoyt, 1976; Frisén, 1979).

Proximal occlusion of the anterior choroidal artery rarely produces visual field defects (Morello and Cooper, 1955), presumably because a collateral circulation develops (Abbie, 1933; Goldberg, 1974). The distal branches which supply the LGN do not anastomose with the lateral choroidal artery (Frisén et al., 1978) (Fig. 4). A distal occlusion of the anterior choroidal artery was produced during removal of the tumour in the present patient (Figs. 1A and B), presumably causing partial infarction of the LGN. This was supported by the finding in computed tomography of decreased attenuation within the right LGN (the $8 \times 8$ voxel array believed to include the LGN contained 12 voxels with an attenuation $\leq 21$ Hounsfield units on the right; only 3 on the left).

The available evidence thus strongly supports the conclusion that most of the visual pathway damage was the result of distal occlusion of the anterior choroidal artery on the right, with partial infarction of the LGN.

The distribution of retinal nerve fibre atrophy with LGN lesions can be predicted on the basis of present anatomical knowledge. It is difficult to recognise by ophthalmoscopy because the fibres involved form a relatively small component of larger bundles. High quality fundus photographs facilitate recognition. Atrophy of nerve fibres

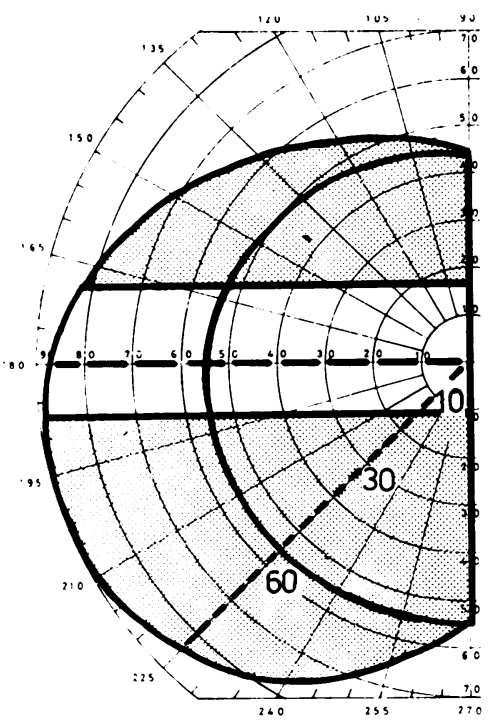

- - horizontal meridian of visual field

-..--lower oblique meridian of visual field

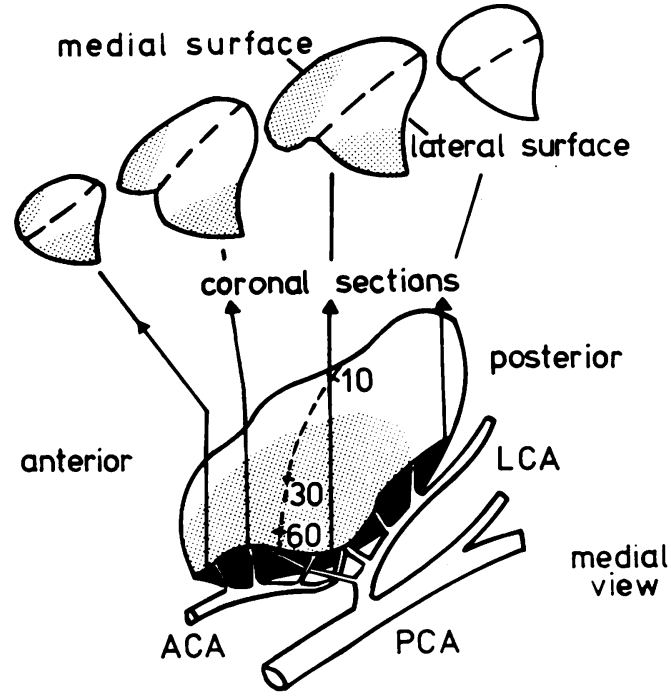

$\square$ territory of ACA

$\square$ territory of LCA

Fig. 4 Schematic diagram of right lateral geniculate body and its binocular visual field. Shaded areas represent presumed extent of lesions producing quadruple sectoranopia. ACA identifies the distal part of the anterior choroidal artery, LCA the proximal part of the lateral choroidal artery, and PCA the ambient segment of the posterior cerebral artery. Modified from Frisén et al., 1978. 
because of infarction in the lateral choroidal artery territory of the LGN is more clearly defined (Frisen et al., 1978). Although the visual field defects associated with the two syndromes of partial infarction of the LGN are quite characteristic, signs of wasting of corresponding retinal nerve fibre bundles are required to confirm the clinical diagnosis.

\section{References}

Abbie, A. A. (1933). The clinical significance of the anterior choroidal artery. Brain, 56, 233-246.

Bynke, H. G. (1966). On early diagnosis and prevention of secondary optic atrophy in papilloedema. Acta Ophthalmologica, 44, 801-813.

Cushing, H., and Eisenhardt, L. (1938). Meningiomas. Their classification, regional behaviour, life history, and surgical end results, pp. 140-155. Charles C. Thomas: Springfield, Illinois. (Reprinted by Hafner Publishing Company: New York, 1962).

Falconer, M. A., and Wilson, J. L. (1958). Visual field changes following anterior temporal lobectomy: their significance in relation to "Meyer's loop" of the optic radiation. Brain, 81, 1-14.

Frisén, L. (1979). Funduscopic correlates of visual field defects due to lesions of the anterior visual pathway. Documenta Ophthalmologica Proceeding Series, 19, 5-16.

Frisén, L., and Holm, M. (1977). Visual field defects associated with choroidal folds. In Neuro-ophthalmology, vol. 9, chapter 19. Edited by J. S. Glaser. C. V. Mosby: St Louis.
Frisén, L., Holmegaard, L., and Rosencrantz, M. (1978). Sectorial optic atrophy and homonymous, horizontal sectoranopia: a lateral choroidal artery syndrome? Journal of Neurology, Neurosurgery, and Psychiatry, 41, 374-380.

Frisén, L., Sjöstrand, J., Norrsell, K., and Lindgren, S. (1976). Cyclic compression of the intracranial optic nerve: patterns of visual failure and recovery. Journal of Neurology, Neurosurgery, and Psychiatry, 39, 1109-1113.

Goldberg, H. I. (1974). The anterior choroidal artery. In Radiology of the Skull and Brain, vol. 2, chapter 36. Edited by T. H. Newton and D. G. Potts, C. V. Mosby: St Louis.

Hoyt, W. F. (1976). Ophthalmoscopy of the retinal nerve fibre layer. Australian Journal of Ophthalmology, 14, 14-34.

Morello, A., and Cooper, I. S. (1955). Visual field studies following occlusion of the anterior choroidal artery. American Journal of Ophthalmology, 40, 796-801.

Roski, R., Spetzler, R. F., Owen, M., Chandar, K., Sholl, J. G., and Nulsen, F. E. (1978). Reversal of seven-year-old visual field defect with extracranialintracranial arterial anastomosis. Surgical Ncur. ology, 10, 267-268.

Traquair, H. M. (1949). An Introduction to Clinical Perimetry, sixth edition, p. 201. Henry Kimpton: London.

Van Buren, J. M., and Baldwin, M. (1958). The architecture of the optic radiation in the temporal lobe of man. Brain, 81, 15-40.

Zeal, A. A., and Rhoton, A. L. (1978). Microsurgical anatomy of the posterior cerebral artery. Journal of Neurosurgery, 48, 534-559. 